\title{
EFEKTIVITAS LAYANAN BIMBINGAN KELOMPOK DENGAN TEKNIK $S E L F$ INSTRUCTION DALAM MENGURANGI KEJENUHAN BELAJAR SISWA KELAS VIII 5 DI SMP NEGERI 04 KOTA BENGKULU
}

\author{
Ulfah Faridah, Arsyadani Mishbahuddin \\ Prodi Bimbingan dan Konseling Fakultas Keguruan dan Ilmu Pendidikan \\ Universitas Bengkulu \\ Ulfah575@gmail.com, arsyadanimishahuddin@yahoo.co.id
}

\begin{abstract}
ABSTRAK
Tujuan penelitian ini adalah untuk mendeskripsikan efektivitas layanan bimbingan kelompok dengan teknik self instruction dalam mengurangi kejenuhan belajar siswa. Metode penelitian ini adalah metode eksperimen dengan one group pre test-post test. Populasi dalam penelitian ini adalah siswa kelas VIII. Sample menggunakan purposive sampling dengan jumlah subjek 10 orang. Data hasil penelitian ini dianalisis menggunakan uji t. Hasil penelitian menunjukkan tingkat kejenuhan belajar siswa mengikuti layanan bimbingan kelompok menurun dengan teknik self instruction, hal ini ditunjukkan dengan nilai $\mathrm{t}=5,470$ dengan taraf signifikansi (2-tailed) sebesar $0,000<0,05$. hal ini menunjukkan bahwa ada pengaruh efektivitas layanan efektivitas layanan bimbingan kelompok dengan teknik self instruction dalam mengurangi kejenuhan belajar siswa kelas VIII 5 di SMP Negeri 04 Kota Bengkulu.

Kata kunci : bimbingan kelompok, kejenuhan belajar

\section{EFFECTIVENESS OF GROUP GUIDANCE SERVICES WITH SELF INSTRUCTION TECHNIQUES IN REDUCING THE SATURATION OF STUDENT LEARNING PROCESS OF CLASS VIII 5 IN JUNIOR HIGH SCHOOL 04 BENGKULU CITY}

\begin{abstract}
The purpose of this study is to describe the effectiveness of group guidance services with selfinstruction techniques in reducing the saturation learning of students. The used method is an experimental technique with one group pretest and posttest. The selected population is students of class VIII. the total of purposive sampling is 10 students. The data is gained and analyzed using the t-test. The results show that the level of saturation within the student learning process was gradually decreased, following the interventions from group guidance services with selfinstruction techniques. It was reflected by the value of $t=5,470$ with a significance level (2tailed) of $0.000<0.05$. It indicates that the effect of the effectiveness of the service of group guidance services with self -instruction techniques in reducing the saturation of students learning process of class VIII 5 in junior high school 04 Bengkulu City.
\end{abstract}

Keywords : group guidance, saturation of student learning process 
Faridah, Mishbahuddin

\section{Pendahuluan}

Menurut Piaget (dalam Dimyati \& Mudjiono, 2010 :13), belajar ialah pengetahuan yang dibentuk oleh individu Sebab individu melakukan interaksi terus menerus dengan lingkungan dan lingkungan terus mengalami perubahan. Siswa sekarang merupakan generasi yang beruntung karena mereka melakukan kegiatan belajar dan interaksi pada keadaan dan lingkungan yang sangat mendukung mereka di berbagai bidang. Saat ini juga lingkungan banyak menuntut mereka untuk memberikan hasil yang terbaik, dalam akademik maupun non akademik.

Seiring berkembangnya kehidupan, lingkungan yang semakin modern inii membuat para siswa semakin mudah dalam belajar, namun ternyata tidak semua siswa mengalami hal tersebut. Setiap siswa memiliki tingkat kemampuan berbeda harus bekerja keras dalam mencapai hal tersebut. Proses belajar yang terus-menerus dilakukan para siswa serta tekanan-tekanan, baik dari dalam diri maupun lingkungannya untuk mencapai prestasi belajar yang maksimal dapat membawa siswa pada batas kemampuan jasmani dan rohaninya.

Pada akhirnya siswa mengalami keletihan fisik dan emosi (mental), meningkatnya sikap depersonalisasi dan menurunnya keyakinan akademis. Selain itu adanya pola berpikir negative terhadap kegiatan dan peristwa belajar yang selalu sama dikerjakan oleh para siswa juga akan juga dapat memicu timbulnya kejenuhan belajar dalam diri siswa yang bias berdampak pada perkembangan pendidikannya. Sutarjo, dkk (2014 : 3), kejenuhan belajar yang terjadi pada siswa harus mendapatkan penanganan, baik penanganan dari siswa sendiri, keluarga, lingkungan rumah maupun lingkungan sekolah. Pada lingkungan sekolah guru bimbingan dan konseling memiliki peran yang penting dalam upaya mengatasi kejenuhan belajar siswa.

Salah satu cara yang dipandang mampu untuk mengurangi kejenuhan belajar siswa yakni melalui bimbingan kelompok. Layanan bimbingan kelompok memiliki tujuan untuk mengembangkan diri pribadi untuk menghasilkan tingkah laku yang efektif, serta bimbingan kelompok merupakan kegiatan layanan yang bertujuan juga dalam menciptakan suasana hati yang nyaman serta kegiatan yang dapat menciptakan suasana baru dalam kehidupan mereka.

Rahmawati (dalam Florentika, dkk, 2016:105) berbagai layanan dan strategii dapat dilakukan untuk mengurangi kejenuhan belajar siswa. Salah satunya dengan menggunakan teknik self instruction. Kejenuhan belajar terjadi jika semakin lama kegiatan belajar mengajar, dan akan semakin berat pula derajat kejenuhan belajar yang akan dialami oleh para siswa. Maka 
ISSN 2599-1221 (Cetak)

ISSN 2620-5343 (Online)

https://ejournal.unib.ac.id/index.php/j_consilia

dari itu penggunaan teknik self instruction diharapkan dapat membantu menguragi kejenuhan belajara para siswa.

Pelaksanaan kegiatan bimbingan dan konseling kelompok juga masih jarang dilakukan, apalagi dengan mengikut sertakan berbagai teknik di dalamnya, maka dari itu peneliti berpendapat bahwa penggunaan teknik self instruction dalam layanan bimbingan kelompok siswa belum pernah dilakukan, sehingga peneliti memilih kegiatan tersebut. Mengacu pada latar belakang di atas, maka peneliti ingin melakukan penelitian tentang efektivitas layanan bimbingan kelompok dengan teknik self instruction dalam mengurangi kejenuhan belajar siswa pada siswa kelas VIII 5 SMP Negeri 04 Kota Bengkulu.

Peneliti mengamati dan menemukan adanya siswa yang membolos saat jam pelajaran, terutama di jam-jam pelajaran yang terkenal dengan sulitnya materi pembelajaran tersebut. Siswa membolos pada jam pelajaran dikarenakan siswa kurang suka sama gurunya, kurang suka sama pelajarannya atau sama sekali tidak paham, serta kurangnya semangat siswa mengikuti pembelajaran tersebut. Tujuan dari adanya pemberian layanan bimbingan kelompok, untuk memberikan deskripsi tingkat kejenuhan belajar siswa sebelum dan sesudah treatment,serta agar siswa mampu mengetahui sebab kejenuhan belajar mereka, mampu berbagi atau mengeluarkan pendapat mereka ketika berkelompok.

\section{Metode Penelitian}

Desain yang digunakan pada penelitian ini adalah eksperimental,yang dimaksud penelitian eksperimental yaitu penelitian yang dilakukan dengan memberikan perlakuan (treatment) tertentu terhadap subjek penelitian dengan menggunakan model (one group pre test - post test design). Prosedur pengambilan sample penelitian dilakukan dengan teknik purposive sampling. Purposive sampling adalah teknik memilih sampel dengan dasar bertujuan, karena untuk menentukan seseorang menjadi sampel atau tidak didasarkan pada tujuan tertentu (Sukardi, 2003:64).

Sampel penelitian ini adalah siswa kelas VIII 5 SMP Negeri 04 Kota Bengkulu. Teknik pengumpulan data dalam penelitian ini menggunakan kuesioner dengan menggunakan model skala Likert. Dari 42 item angket kejenuhan belajar yang dibuat dan disebarkan, sebanyak 14 item dinyatakan tidak valid dan menyisakan 28 item angket kejenuhan belajar yang valid. Sesudah angket dinyatakan valid, maka akan digunakan sebagai alat ukur untuk mengetahui 
Faridah, Mishbahuddin

tingkat kejenuhan belajar siswa. Uji validitas instrument di uji dengan menggunakan bantuan SPSS v.23.

\section{Tabel 1 \\ Hasil Uji Reliabilitas}

\begin{tabular}{cc}
\hline Cronbach's Alpha & No of Items \\
\hline .905 & 28
\end{tabular}

Untuk memperoleh reliabilitas pada suatu instrument maka dalam penelilitian ini menggunakan rumus Alpha Croanbach's dengan bantuan SPSS v.23. Berdasarkan tabel 1, diperoleh Alpha Croanbach's sebesar 0,905 yang dapat dikatakan reliable. Untuk menguji hipotesis yang ada penelitian ini, rumus yang digunakan adalah rumus uji-t. Uji-t digunakan untuk mencari data ada atau tidaknya perbedaan sebelum dan sesudah pemberian layanan bimbingan kelompok dengan teknik self instruction dalam menurunkan kejenuhan belajar siswa kelas VIII 5 SMP Negeri 04 Kota Bengkulu.

\section{Hasil dan Pembahasan}

Deskripsi data yang disajikan dalam penelitian ini adalah dengan deskripsi data dari tingkat kejenuhan belajar sebelum, sesudah dan cara pelaksanaan layanan bimbingan kelompok dengan teknik self instruction dalam mengurangi kejenuhan belajar siswa. Thursan Hakim (dalam Zuni \& Christiana, 2014:2), mendefinisikan kejenuhan belajar merupakan suatu kondisi mental seseorang saat mengalami rasa bosan dan lelah yang amat sangat sehingga mengakibatkan timbulnya, lesu, tidak bersemangat melakukan aktifitas belajar atau menurunya motivasi. Dalam penelitian ini, kejenuhan belajar dilihat dari berbagai aspek yang saling berkaitan. Adapun aspek tersebut yaitu kelelahan emosional, kelelahan fisik, kelelahan kognitif serta kurangnya motivasi. Aspek tersebut dibahas dan didalam diskusi dibuat dan dipraktekkan teknik instruksi diri yang diharapkan mampu membawa perubahan pada diri siswa.

Deskripsi tentang kejenuhan belajar siswa diperoleh dari hasil penyebaran kuesioner kepada 32 responden yang menjadi sampel penelitian, kemudian memilih subjek berjumlah 10 orang siswa untuk diberi perlakuan. Pemberian pre test pada tanggal 15 Maret 2019 dengan jumlah respnden 10 orang siswa diperoleh hasil : 
Tabel 2

Hasil Pre test Kejenuhan Belajar Siswa

\begin{tabular}{lcc}
\hline \multicolumn{1}{c}{ Kategori } & Frekuensi & Persentase \\
\hline Tinggi $(94-115)$ & 0 & 0 \\
\hline Sedang $(72-93)$ & 10 & $100 \%$ \\
\hline Rendah $(50-71)$ & 0 & 0 \\
\hline Sangat Rendah $(28-49)$ & 0 & 0 \\
\hline Total & 10 & $100 \%$
\end{tabular}

Berdasarkan tabel 2, dapat dilihat siswa yang menjadi subjek sebanyak 10 orang memiliki skor kategori sedang dengan persentase 100\%. Hasil pretest menunjukkan bahwa tingkat kejenuhan belajar siswa cenderung berada pada kategori sedang.

Peneliti memberikan treatment sebanyak 4 kali pertemuan, yaitu layanan bimbingan kelompok dengan teknik self instruction. Menurut Prayitno (1995: 178) bimbingan kelompok adalah suatu kegiatan yang dilakukan oleh sekelompok orang dengan memanfaatkan dinamika kelompok. Artinya, semua peserta dalam kegiatan kelompok saling berinteraksi, bebas mengeluarkan pendapat, menanggapi, memberi saran, dan lain-lain sebagainya apa yang dibicarakan itu semuanya bermanfaat untuk diri peserta yang bersangkutan sendiri dan untuk peserta lainnya. Safaria (2004: 74), self instruction merupakan teknik kognitif yang paling popular yang sering digunakan untuk anak dan telah banyak diaplikasikan dalam lingkup yang luas pada gangguan anak. Orang dewasa menggunakan instruksi diri berupa kalimat pernyataan ketika mereka berhadapan dengan permasalahan dalam suatu pekerjaan tertentu, dengan tujuan mengubah cara mereka merasakan kesulitan tersebut.

Kegiatan ini dilakukan dengan bentuk kelompok dengan metode ceramah dan tanya jawab, dilakukan sebanyak 4 kali pertemuan dengan 10 orang. Setelah diberikan pretest dan treatment berupa layanan bimbingan kelompok dengan teknik self instruction, selanjutnya dilakukan kembali penyebaran angket untuk mengetahui perkembangan siswa. Post test dilakukan pada tangga 6 April 2019 pada 10 siswa yang menjadi anggota kelompok. Berikut hasil berdasarkan penyebaran angket post -test. 
Tabel 3

\section{Hasil Post test Kejenuhan Belajar}

\begin{tabular}{lcc}
\hline \multicolumn{1}{c}{ Kategori } & Frekuensi & Persentase \\
\hline Tinggi $(94-115)$ & 0 & 0 \\
\hline Sedang $(72-93)$ & 3 & $30,00 \%$ \\
\hline Rendah $(50-71)$ & 6 & $60,00 \%$ \\
\hline Sangat Rendah $(28-49)$ & 1 & $10,00 \%$ \\
\hline Total & 10 & $100 \%$ \\
\hline
\end{tabular}

Berdasarkan tabel 3, dari 10 siswa yang diberikan treatment memiliki skor kategori sedang berjumlah 3 orang dengan persentase 30\%. Siswa yang memiliki skor kategori rendah berjumlah 6 orang dengan persentase $60 \%$. Sedangkan siswa yang memiliki skor kategori sangat rendah berjumlah 1 orang dengan persentase 10\%. Dan ini menunjukkan bahwa hasil post test cenderung berada dalam kategori rendah.

Setelah dilakukan pre test, treatment berupa layanan bimbingan kelompok dengan teknik self instruction dan post test pada 10 siswa yang menjadi sample penelitian menunjukkan bahwa adanya perbedaan skor dan mean pada skor pre-test dan post-test kejenuhan belajar, yang diketahui pada skor pre test sebanyak 10 orang siswa dalam kategori sedang dengan rata-rata 80. Kemudian setelah diberikan treatment, skor kejenuhan belajar diperoleh 3 orang siswa dalam kategori sedang, 6 orang siswa dalam kategori rendah, dan 1 orang siswa dalam kategori sangat rendah. Dengan rata-rata post-test siswa sebesar 65,3. Berdasarkan data yang dimiliki untuk uji t didapati hasil berikut:

\section{Tabel 4} Hasil Uji t

\begin{tabular}{lcc}
\hline & T & Sig. \\
\hline Pre-test, Post-test & 5.470 & .000 \\
\hline
\end{tabular}

Dari tabel 4, dapat dijelaskan bahwa ada efektivitas layanan bimbingan kelompok dengan teknik self instruction dalam mengurangi kejenuhan belajar siswa berdasarkan nilai t (5.470). penelitian ini ditunjukkan dengan nilai $\mathrm{P}<0,005$ yaitu sebesar 0,000 , yang berarti hipotesis nol (Ho) ditolak. Dan data tersebut dapat disimpulkan bahwa hipotesis penilitian (Ha) diterima yang berarti penelitian ini, menujukkan adanya efektivitas layanan bimbingan kelompok dengan teknik self instruction dalam mengurangi kejenuhan belajar siswa. 
Pada penelitian ini, salah satu upaya dalam mengurangi kejenuhan belajar adalah dengan melakukan kegiatan layanan bimbingan kelompok dengan teknik self instruction ini bertujuan agar siswa mampu mengetahui sebab kejenuhan belajar mereka, mampu berbagi atau mengeluarkan pendapat mereka ketika berkelompok. Dalam melakukan teknik self instruction dengan menulis berbagai instruksi diri yang telah dibuat oleh peneliti yang terkait dengan materi yang diberikan pada setiap pertemuannya lalu para anggota mempraktikkannya dan mengingatnya.

Pertemuan keseluruhan pada penelitian ini sebanyak 5 kali. Yaitu 1 kali pre-test, 4 kali treatment dan terakhir post-test. Selama 4 kali pertemuan pemberian treatment berupa layanan bimbingan kelompok dengan teknik self instruction dilakukan selama 40 menit. Pada pertemuan pertama siswa diberikan pre test sambil melakukan perkenalan dan memberitahu tujuan dari peneliti. Pada pertemuan kedua, diberikan materi berupa prestasi belajar, yang membahas bagaimana cita-cita mereka, dan berbagi tips. Pada pertemuan ketiga diberikan materi berupa kelelahan fisik, yang meliputi keadaan diri mereka, yang mana berdampak pada semangat belajar mereka. Pada pertemuan keempat, diberikan materi tentang gangguan konsentrasi. Dengan permainan konsentrasi siswa mampu memahami pentingnya konsentrasi dalam belajar. Pertemuan kelima, diberikan materi menumbuhkan motivasi. Materi ini berisi tentang cara menumbuhkan motivasi baik untuk diri sendiri maupun untuk belajar.

Setelah diberikan materi terakhir, peneliti langsung memberikan angket post test pada siswa. Hasil yang didapat adanya penurunan dari hasil pre test ke hasil post test. Dengan ratarata pre test 80 dan rata-rata post test 65,3. Jadi kesimpulannya adalah layanan bimbingan kelompok dengan teknik self instruction berdampak pada penurunan kejenuhan belajar siswa dengan materi dan kegiatan yang dilakukan selama pemberian treatment. Siswa mulai memahami bahwa kejenuhan yang mereka alami bisa berdampak buruk jika mereka menuruti dan tidak mau merubahnya sedikit. Adapun kesungguhan para siswa selama kegiatan berlangsung menunjukkan kejenuhan belajar dalam diri mereka mulai menurun.

\section{Kesimpulan}

Berdasarkan hasil penelitian yang telah dilaksanakan, maka dapat disimpulkan bahwa kejenuhan belajar siswa sebelum diberikan layanan bimbingan kelompok dengan teknik self instruction berada pada kategori sedang dengan skor rata-rata 80. Selanjutnya pemberian 
Faridah, Mishbahuddin

treatment berupa layanan bimbingan kelompk dengan teknik self instruction selama 4 kali pertemuan. Kemudian pemberian post test setelah diberikan layanan bimbingan kelompk dengan teknik self instruction berada pada kategori rendah dengan skor rata-rata 65,3. Jadi, dapat disimpulkan bahwa terdapat efektivitas layanan bimbingan kelompk dengan teknik self instruction dalam mengurangi kejenuhan belajar siswa kelas VIII 5 SMP Negeri 04 Kota Bengkulu.

\section{Daftar Pustaka}

Alamri, Nurdjana. (2015). Layanan Bimbingan Kelompok Dengan Teknik Self Management Untuk Mengurangi Perilaku Terlambat Masuk Sekolah (Studi Pada Siswa Kelas X SMA 1 Gebog Tahun 2014/2015). Jurnal Konseling Gusjigang, 1(1).

Dewantoro, A, Legowo, E, Chadidjah Dkk (2016). Keefektifan Teknik Self instruction Untuk Mereduksi Kecemasan Menghadapi Ujian Pada Peserta Didik SMA. Jurnal Bimbingan dan Konseling, 4(1).

Dimyati \& Mujiono. (2010). Belajar Dan Pembelajaran. Jakarta : Rineka Cipta

IPT. Edi Sutarjo, Dewi ,Arum WMP., Ni. Kt. Suarni. (2014). Efektifitas Teori Behavioral Teknik Relaksasi Dan Brain Gym Untuk Menurukan Burnout Belajar Pada Siswa Kelas VIII SMP Laboratorium Undiksha Sigaraja Tahun Pelajaran 2013 / 2014. E-Journal Undiksa. 2(1).

Florentika, K., Santoso, D, B., Simon, I, M. (2016). Keefektifan Teknik Self-Instruction Untuk Meningkatkan Kepercayaan Diri Siswa SMP. Jurnal Bimbingan dan Konseling, 1(3), 104111.

Khusumawati, Z, E., \& Cristiana, E. (2014). Penerapan Kombinasi Antara Teknik Relaksasi Dan Self-Instruction Untuk Mengurangi Kejenuhan Belajar Siswa Kelas XI IPA 2 SMA Negeri 22 Surabaya. Jurnal UNESA. Vol 5 No.1. Diunduh 11 Desemer 2017.

Prayitno. (1995). Layanan Bimbingan Dan Konseling Kelompok (Dasar Dan Profil). Jakarta : Ghalia Indonesia.

Raqfika, U., Tjalla, A, dan Chanum, I. (2016). Penerapan Konseling Individu Dengan Teknik Instruksi Diri Dalam Pendekatan Terapi Kognitif-Perilaku Untuk Mengurangi Kejenuhan Pada Mahasiswa (Penelitian Subjek Tunggal Terhadap Mahasiswa Fakultas Ilmu Pendidikan Universitas Negeri Jakarta). Jurnal Bimbingan Konseling, 5(1), 126-133.

Safaria, Triantoro. (2004). Terapi Kognitf-Perilaku Untuk Anak. Yogyakarta : Graham Ilmu.

Sukardi. (2003). Metodologi Penelitian Pendidikan Kompetensi dan Prakteknya. Jakarta: Bumi Aksara. 